\title{
Research on the Recoil Optimization of a Certain Type of Rifle Based on ADAMS
}

\author{
Zhensen Zhao, Keyin Wang \\ Department of Vehicles and Electrical Engineering, Army Engineering University, Shijiazhuang \\ Campus, Shijiazhuang 050003, China \\ E-mail:514711895@qq.com,2197816238@qq.com
}

Keywords: component; formatting; style; styling; insert

\begin{abstract}
The impact of gun frame on casing is one of the main causes of rifle recoil, in order to reduce the recoil effect of a certain type of rifle, the virtual prototype of the rifle is established and validated by Adams Dynamic simulation software, and a simulation optimization method is proposed, which takes the velocity of the casing after the impact of the gun machine and the casing as the objective function. Based on the Multi Island Genetic algorithm, the optimization results of the stiffness, the stiffness of the hammer spring, the stiffness of the buffer spring, the gun machine (including the gun frame and the gun machine) and the quality of the hammer are optimized, and the optimization effect is obvious, which provides a reference for the related research of reducing recoil.
\end{abstract}

\section{Introduction}

Rifles are currently the main battle equipment of individual combat weapons in various countries in the world. Because of their characteristics such as great power, high precision, and good portability, they are of great significance in the history of weapon development in the world. However, the rifle will generate a large recoil force during the shooting process, which will not only greatly affect the accuracy of shooting, but also extend the time for the shooter to re-target. During the firing process, the impact of the bolt box on the casing is one of the main reasons for the rifle recoil force. The performance parameters of the recoil spring, the hammer spring and the buffer spring will affect the performance parameters of these components. One of the effective ways to reduce recoil ${ }^{[1]}$.

This paper takes a certain type of automatic rifle as the research object, takes the virtual prototype established by ADAMS dynamics simulation software as the research foundation, selects the MIGA multi-island genetic algorithm, and rationally configures the performance parameters of related components to reduce the rifle firing recoil. The research method of this article also has certain reference significance for the research on reducing the recoil force of other firearms weapons.

\section{Establishment of Objective Function}

The rifle recoil is mainly caused by the rapid expansion of gunpowder gas and the impact on the casing when the bolt is recoiled. This paper selects the influence of the recoil impact caused by the 
impact of the casing on the back seat of the rifle frame as the object of study. The speed is optimized for the objective function. The objective function is established in an ideal state, so the following prerequisites must be guaranteed.

a) Collisions in the recoil of the bolts are elastic collisions;

b) The recoil spring, hammer spring and cushion spring are ideal non-damping springs;

c) Before and after the collision of the bolt, bolt frame, machine hammer and casing, it can be considered as a whole.

The slamming process of the bolting machine includes two phases of sitting and sitting in the back seat and colliding between the frame and the casing. The energy conservation equation in the first phase is Equation (1).

$$
\mathrm{E}_{0}=\mathrm{E}_{1}+\mathrm{E}_{2}+\mathrm{E}_{3}+\mathrm{E}_{4}+\mathrm{E}_{5}+\mathrm{E}_{6}
$$

In Equation (1), $E_{0}$ and $E_{6}$ are the kinetic energy during the start of the back seat of the gun frame and the internal energy loss during the recoil. They can be regarded as constant for each shot; $E_{1}, E_{2}$ and $E_{3}$ respectively represent the recoil spring when the seat is in the back seat. The energy stored in the hammer spring and the buffer spring; E4 is the kinetic energy of the bolt mechanism, the bolt frame, and the hammer when seated back; $E_{5}$ is the work done by pulling the shell resistance.

$$
\mathrm{E}_{\mathrm{i}}=\int \mathrm{k}_{\mathrm{i}} \mathrm{x}_{\mathrm{i}} \mathrm{dx}_{\mathrm{i}}(\mathrm{i}=1,2,3)
$$

In Equation (2), xi and ki respectively represent the compression stroke and stiffness of the recoil spring, the hammer spring and the cushion spring during the recoil of the bolt mechanism.

$$
\begin{gathered}
\mathrm{E}_{4}=\frac{\mathrm{mv}_{1}^{2}}{2} \\
\mathrm{~m}=\mathrm{m}_{1}+\mathrm{m}_{2}+\mathrm{m}_{3}
\end{gathered}
$$

In Equation (3) and (4), $m_{1}, m_{2}, m_{3}$ respectively represent the quality of the bolt machine, gun frame, and hammer.

$$
\begin{gathered}
\mathrm{E}_{5}=\int \mathrm{F}_{\phi} \mathrm{dx}_{4} \\
\mathrm{~F}_{\phi}=\pi\left\{\mathrm{f}_{0} \mathrm{l}_{\mathrm{k}}\left[\mathrm{pd}_{1}+2 \mathrm{e}_{1} \delta\left(\Delta-\frac{2 \mathrm{x}_{4} \alpha}{\mathrm{d}_{\mathrm{pj}}}\right)\right]-\frac{1}{4} \mathrm{~d}_{1}^{2} \mathrm{p}\right\}
\end{gathered}
$$

In Equation (5), $\mathrm{f}_{0}$ is the friction coefficient between the shell and the magazine; $\mathrm{l}_{\mathrm{k}}$ is the total length of the shell in the magazine; $\mathrm{p}$ is the pressure of the gunpowder gas in the shell; $\mathrm{d}_{1}$ is the inner diameter of the shell; $\mathrm{e}_{1}$ is the elastic modulus of the shell material; $\delta$ is the shell Wall thickness; $\Delta$ is the relative amount of contraction between the outer surface of the shell and the magazine wall; $\mathrm{d}_{\mathrm{pj}}$ is the average diameter of the shell; $\alpha$ is the semi-taper angle of the cone-shaped part of the shell; $\mathrm{x}_{4}$ is the backward stroke of the shell.

The second stage of the energy conservation and momentum balance equation is Equation (7) and (8).

$$
\begin{aligned}
& m v_{1}=M v+m v_{2} \\
& m v_{1}^{2}=m v_{2}^{2}+M v^{2}
\end{aligned}
$$

In Equation (7) and (8), $\mathrm{M}$ is the mass of the whole gun except for the bolt, bolt frame, hammer, and shell; $\mathrm{v}$ is the speed of the body after collision; $\mathrm{v}_{1}, \mathrm{v}_{2}$ are the speed of the bolt before and after 
the collision.

Therefore, the objective function can be expressed as:

$$
v=\frac{\sqrt{8 m\left(E_{0}-E_{6}-\int F_{\phi} d x_{4}-\iint k_{i} x_{i} d x_{i} d i\right)}}{M+m}(i=1,2,3)
$$

\section{Establish and Validate Virtual Prototyping}

\subsection{Virtual Prototyping and Verification}

\subsubsection{Prototype Modeling}

The quality of each component in the model is an important parameter for the virtual prototype [2]. This article uses the direct assignment method to assign quality to each component. As shown in Table I, the virtual prototype is shown in Fig 1.

Table I Quality of Various Parts of the Model

\begin{tabular}{|c|l|l|c|l|c|}
\hline $\begin{array}{c}\text { Part } \\
\text { Name }\end{array}$ & Bolt & $\begin{array}{c}\text { Bullet } \\
\text { box }\end{array}$ & $\begin{array}{c}\text { Ham } \\
\text { m-er }\end{array}$ & Piston & $\begin{array}{c}\text { Gun } \\
\text { body }\end{array}$ \\
\hline $\begin{array}{l}\text { Quality } \\
\text { (kg) }\end{array}$ & 0.078 & 0.42 & 0.052 & 0.0284 & 2.6716 \\
\hline
\end{tabular}

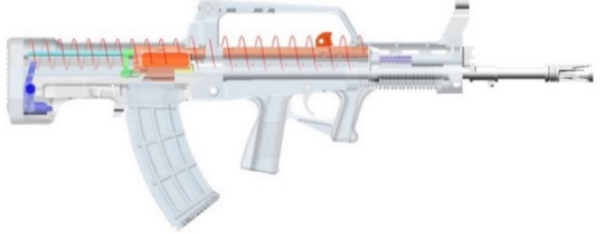

Figure 1 Rifle virtual prototype

\subsubsection{Virtual Prototyping Script}

In order to make the fixed pair of the gun body and the ground fail at the moment before the collision between the bolt and the gun ${ }^{[3]}$, the translational assistant activates and the direction is along the axis of the barrel, and the simulation script is written as shown in Fig 2.

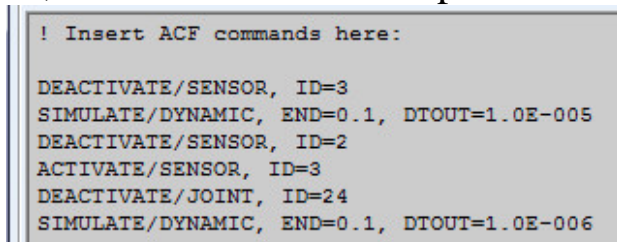

Figure 2 Simulation script

\subsection{Validate Virtual Prototyping}

The speed and displacement of the gun frame are the core parameters to verify the correctness of the virtual prototype of the rifle. The speed and displacement curves of the gun frame in the virtual prototype established in this paper are shown in Fig $3^{[4]}$. The instantaneous speed of the gun frame at the key position is selected and compared with the experimental data. In Table II, the errors are all less than $8 \%$, which meets the engineering calculation requirements. 


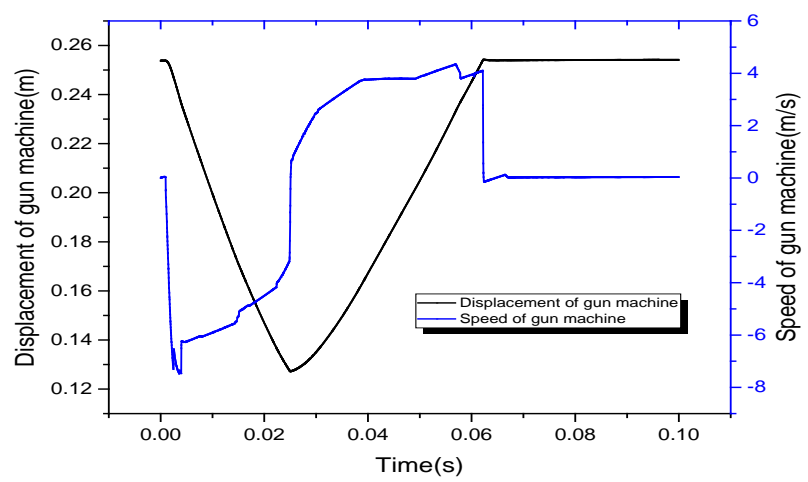

Figure 3 The speed and displacement curve of the gun frame

Table II Key Point Speed of Gun Frame

\begin{tabular}{|l|l|l|l|}
\hline $\begin{array}{l}\text { Gun frame } \\
\text { speed(m/s) }\end{array}$ & $\begin{array}{l}\text { Emulation } \\
\text { datas }\end{array}$ & Test datas & Error \\
\hline Recoil start & 6.27 & 6.75 & $7.11 \%$ \\
\hline Recoil in place & 3.05 & 2.97 & $2.69 \%$ \\
\hline $\begin{array}{l}\text { Resumption } \\
\text { begins }\end{array}$ & 0.76 & 0.78 & $2.56 \%$ \\
\hline $\begin{array}{l}\text { Resumption in } \\
\text { place }\end{array}$ & 4.06 & 3.78 & $7.41 \%$ \\
\hline
\end{tabular}

\section{Optimization Analysis}

\subsection{Parameter Setting of Multi-island Genetic Algorithm}

Multi-island Genetic Algorithm parameter settings are shown in Table III.

Table III Algorithm Parameter Settings

\begin{tabular}{cc}
\hline Parameters & Datas \\
\hline Sub-Population Size & 10 \\
Number of Islands & 10 \\
Rate of Crossover & 1.0 \\
Rate of Mutation & 0.01 \\
Rate of Migration & 0.01 \\
Penalty Multiplier & 1000 \\
Penalty Exponent & 2 \\
\hline
\end{tabular}

\subsection{Optimization Analysis of Design Variables}

Based on the theoretical results of the above objective function, select the stiffness of the complex spring, hammer spring stiffness, buffer spring stiffness, gun machine (including gun frame and gun machine), hammer quality 5 parameters to optimize, according to engineering practice experience to select the range of parameters, optimization results as shown in Table IV ${ }^{[5]}$. 
Table IV Parameter Optimization Analysis

\begin{tabular}{|c|c|c|c|c|}
\hline $\begin{array}{c}\text { Parameter } \\
\text { name }\end{array}$ & Initial & Lower & Ceiling & $\begin{array}{c}\text { Optimi-zat } \\
\text { ion results }\end{array}$ \\
\hline $\begin{array}{c}\text { Stiffness of complex } \\
\text { spring(N/m) }\end{array}$ & 207.4 & 150 & 250 & 241.21 \\
\hline $\begin{array}{c}\text { Hammer Spring } \\
\text { stiffness(N/m) }\end{array}$ & 170 & 100 & 250 & 218 \\
\hline $\begin{array}{c}\text { Stiffness of cushion } \\
\text { Spring(N/m) }\end{array}$ & 30583 & 25000 & 35000 & 29509 \\
\hline $\begin{array}{c}\text { Quality of gun } \\
\text { machine(kg) }\end{array}$ & 0.498 & 0.4 & 0.6 & 0.556 \\
\hline Hammer Quality(kg) & 0.052 & 0.04 & 0.06 & 0.054 \\
\hline Objective function & 0.9363 & & & 0.6549 \\
\hline
\end{tabular}

\subsection{Comparison and Analysis of Objective Function Before and After Optimization}

After the optimized parameter value is taken into the virtual prototype, the optimized objective function value is obtained and the objective function value pairs, shown in Table V and Fig. 4.

Table V Comparison of Objective Function Optimization Before and After

\begin{tabular}{cccc}
\hline $\begin{array}{c}\text { Objective } \\
\text { function }\end{array}$ & $\begin{array}{c}\text { Before } \\
\text { optimization }\end{array}$ & $\begin{array}{c}\text { After } \\
\text { optimization }\end{array}$ & $\begin{array}{c}\text { Percent } \\
\text { optimization }\end{array}$ \\
\hline $\begin{array}{c}\text { Maximum } \\
\text { speed of gun } \\
\text { body }\end{array}$ & $0.936(\mathrm{~m} / \mathrm{s})$ & $0.655(\mathrm{~m} / \mathrm{s})$ & $30.02 \%$ \\
\hline
\end{tabular}

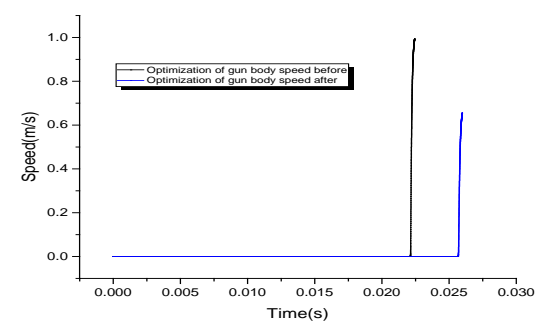

Figure 4 The speed of the gun body when the bolt is in place before and after optimization

It can be seen that the objective function is reduced by $30.02 \%$ after optimizing the parameters, the effect is more obvious, the recoil time is 0.0032, and the effect is small and can be neglected.

\section{Conclusion}

This article takes a certain type of rifle as the research object, uses ADAMS dynamics simulation software to establish and verify the virtual prototype of this type of rifle, uses multi-island genetic algorithm to optimize the relevant parameters of the rifle, and effectively reduces the rifle firing process. The impact of the bolt machine on the casing, thereby reducing the impact of squat gun recoil. The research method of this paper provides a reference for the research on the recoil reducing force of other firearms weapons. 


\section{References}

[1] Zhang Junnuo,Hua Binbin, and Kang Xiaoyong, "Research of Multi-objective Genetic Algorithm in Multidisciplinary Optimization of a Certain Heavy Gun Machine” NEW TECHNOLEGY \& NEW PROCESS, vol .11, Nov. 2015, pp . 45-47.

[2] Zhang Ben-jun, Wang Rui-lin, Li Yong-jian, and Li Zhi-yong, “ Structural optimization for a machine-gun mount based on BP neural network and genetic algorithm ”JOURNAL OF VIBRATION AND SHOCK, vol 30,2011, pp. 142-144.

[3] Yang Xiaoyu, Wang Ruilin, Li Yonjian and Chen Jinxi, “ Method of reducing the recoil force of a pistol based on a virtual prototype ” JOUENAL OF MACHINE DESIGN, vol.29, Mar.2012, pp. 61-64

[4] Zhao Yan, Liao Zhenqiang, "Dynamic Simulation Analysis on Floating Apparatus of Machine Gun Based on ADAMS ” Ordnance INDUSTRY Automation, vol.33,2014, pp. 84-47

[5] Zhang Benjun, Wang Ruilin, Zheng LIping and Li Yongjian, "Dynamic response of human body under impact of machine gun” JOURNAL OF VIBRATION AND SHOCK, vol. 36, No.9, 2017, pp.195-201. 